\title{
An Interpretation of the Miramichi Bay Magnetic Anomaly, New Brunswick*
}

\author{
P. H. McGRATH \\ Geological Survey of Canada, Ottawa, Ont.
}

The paper presents a quantitative interpretation of the prominent magnetic anomaly centered over the northern half of Miramichi Bay (Geol. Surv. Can., Aeromagnetic Map 805 G, Chatham, New Brunswick, Sheel $21 \mathrm{P} / 3)$. This report represents a part of a continuing program of magnetic interpretation of crustal structure in the Canadian Appalachian Region.

\section{Magnetic Interpretation}

The location of the profile (N-S) selected for interpretation of this anomaly is shown in Figure 1. The magnetic data comprising this figure were compiled from information recorded at a 1000-foot mean terrain clearance along north-south flight lines spaced at approximately halfmile intervals. The contour interval is 10 gammas.

Interpretation of the magnetic anomaly profile (N-S) was carried out using a computer curve-matching technique (McGrath and Hood, in preparation). In order to compare the observed anomaly curve (Figure 2) with calculated model curves, the observed anomaly profile (N-S) was digitized using a sampling interval of three-tenths of a mile. A linear regional variation, which increases at the rate of 4.8 gammas per mile from east to west and 2.8 gammas per mile from south to north (Aeromagnetic Map $805 \mathrm{G}$ ) was removed from the observed data before any comparisons with model curves were undertaken.

The dipping-dyke model was chosen for interpretation of the Miramichi Bay magnetic anomaly. The assumptions made in using this model for interpretation are: 1) the intensity of magnetization is constant throughout the model but its direction is not necessarily parallel to the earth's magnetic field, 2) it has infinite strike length and extends to infinite depth, and 3 ) it has parallel sides and a horizontal upper surface.

The observed data (N-S) were compared with model curves for the dipping dyke using a computer program. A best set of model parameters was selected by the computer such that the standard deviation $(\nabla)$ of the residuals was a minimum, where

$$
\begin{aligned}
& \boldsymbol{r}=\left[\frac{\sum_{i=1}^{N}\left(\Delta T_{i \text { obs }}-\Delta T_{\text {i calc }}\right)^{2}}{N-1}\right]^{\frac{1}{2}} \\
& \mathbf{T}_{\text {iobs }} \quad=\text { observed data along profile N-S } \\
& \mathrm{T}_{\text {icalc }} \quad=\text { calculated data using the dipping dyke model } \\
& \mathrm{N} \quad=\text { number of data points along } \mathrm{N}-\mathrm{S} \text {. }
\end{aligned}
$$

The results of the interpretation are shown in Figure 2. The disturbing zone is centered under the point $O$ along N-S (Figure 1). It is 19,000 feet wide, the depth to its uppe $r$ surface is 6000 feet, and it possesses an average effective susceptibility contrast of $2300 \times 10^{-6}$ cgs units. In addition, assuming that the remanent magnetization is parallel to the induced magnetization or that the induced magnetization is dominant over the remanent magnetization, the dyke is essentially vertical.

The minimum standard deviation obtained from the comparison of observed data and the model curves for the dipping dyke was 15 gammas. Convergence to solutions with larger standard deviations may be obtained by extending the profile N-S to the southeast. However, because of interference with the large magnetic low to the south of the Miramichi Bay anomaly, such solutions are not considered as reliable as that shown in Figure 2.

\section{Geological Interpretation}

The pre-Carboniferous basement rocks of the Bathurst area have been studied by Skinner 


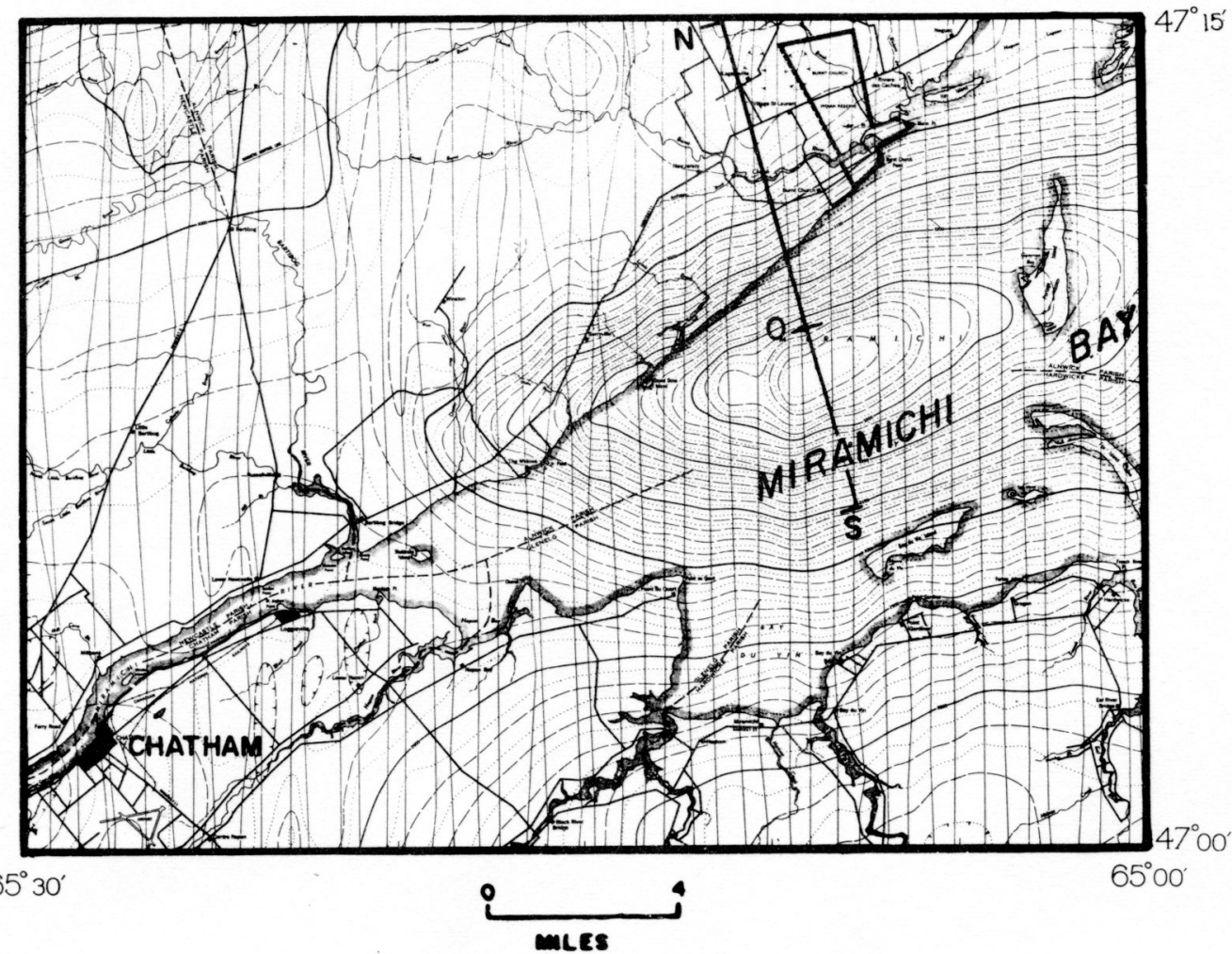

Figure 1 The total intensity mognetic map (contour interval 10 gammas) of the Miramichi Bay area showing profile N-S. The point 0 is situated over the center of the disturbing body.

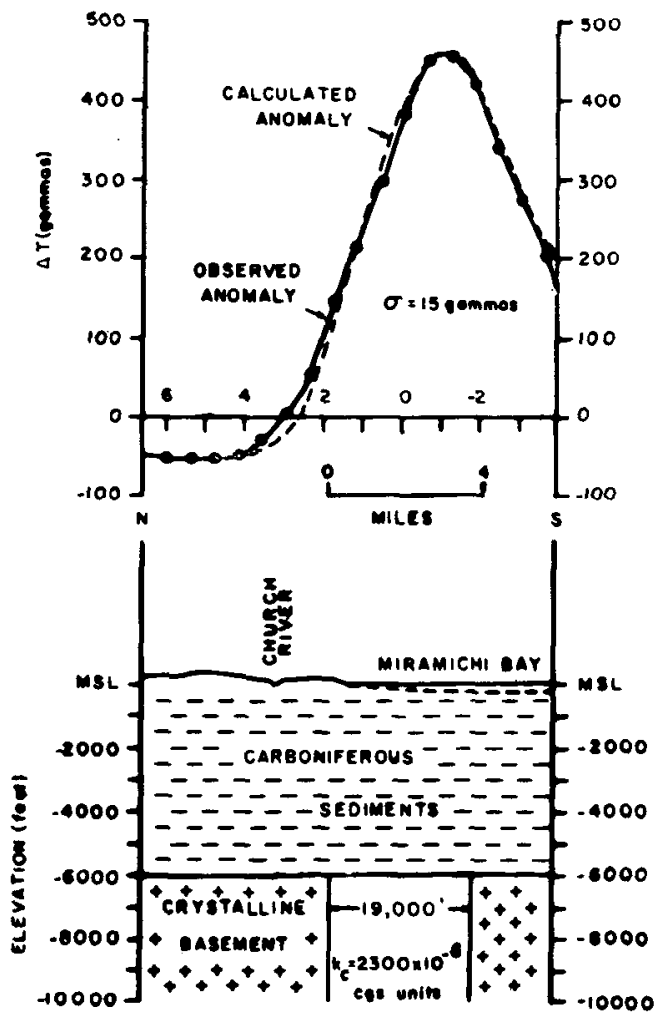

Figure 2 Calculated and observed total intensity magnetic anomaly profile (N-S) of the Miramichi Bay anomaly with interpreted structure in cross-section. 
(1956), Smith (1957) and Davies (1966). The structural grain in these rocks is dominated by northeast - striking folds with steeply dipping axial planes and axes which plunge to the northeast and southwest. Smith (1957) notes a spatial relationship between outcrops of Tetagouche sediments (iron formation and ferruginous cherts) and volcanics (spilites and greenstones), Devonian basic sills and dykes, and prominent local aeromagnetic anomalies.

To the east of the Bathurst area nearly flat-lying Carboniferous strata unconformably overlie these older Paleozoic rocks. Howie and Cumming (1963) have studied the regional variations in thickness of the various Carboniferous members of this unit. They show a local thickening of the Carboniferous section in the Miramichi Bay area.

The Miramichi Bay magnetic anomaly is probably caused by a sedimentary-basic volcanic sequence or by basic intrusives, such as a dyke swarm. The top of this disturbing zone is situated at a depth of 6000 feet. Resting unconformably above this is a 6000 foot thick section of Carboniferous sediments (Figure 2).

The nature of this local increase in thickness of the Carboniferous section in the Miramichi Bay area has been discussed by Howie and Cumming (1967).

\section{References cited}

DAVIES, J. L., 1966, Geology of Bathurst - Newcastle Area, N. B. ; in Geol. Assoc. Can. and Min. Assoc. Can. guidebook, Geology of Parts of Atlantic Provinces, W. H. Poole editor, p. $33-43$.

GEOLOGICAL SURVEY OF CANADA, 1965, Aeromagnetic Map 805 G; Scale 1 inch to 4 miles.

HOWIE, R. D. and CUMMING, L. M., 1963, Basement features of the Canadian Appalachians; Geol. Surv. Can. Bull. 89.

1967, Possible basement graben beneath Miramichi Bay, New Brunswick; Geol. Assoc. Can. Spec. Paper no. 4, p. 283-292.

SKINNER, Ralph, 1956, Geology of the Tetagouche Group; unpublished Ph. D. Thesis, McGill University.

SMITH, C. H., 1957, Bathurst-Newcastle Area; Northumberland, Restigouche and Gloucester counties, New Brunswick; Geol. Surv. Can., Map 1-1957. 